\title{
Post-traumatic stress disorder: new directions in pharmacotherapy
}

\section{Ben Green}

\begin{abstract}
SUMMARY
As many as $10 \%$ of the population experience post-traumatic stress disorder (PTSD) at some time in their lives. It often runs a severe, chronic and treatment-resistant course. This article reviews the evidence base for typically recommended treatments such as cognitivebehavioural therapy (CBT), eye movement desensitisation and reprocessing and selective serotonin reuptake inhibitors (SSRIs). It tabulates the major randomised controlled trials of SSRIs and trauma-focused CBT and reviews research on novel treatments such as ketamine, MDMA, quetiapine, propranolol and prazosin.
\end{abstract}

\section{DECLARATION OF INTEREST}

None.

Post-traumatic stress disorder (PTSD) is relatively common, affecting $6-10 \%$ of all individuals at some time in their lives (Kessler 2005). Key symptoms include nightmares, intrusive memories and sensory impressions (flashbacks) and avoidance behaviour. There is a considerable risk of comorbid problems (e.g. depression or alcohol misuse), and PTSD is a source of disability and increased suicide risk. Table 1 shows the relative frequencies of different symptoms in people with PTSD.

Despite the prevalence of PTSD, traditional treatments are relatively limited in their success. In 1999, the World Health Organization's Management of Mental Disorders concluded that 'PTSD is a severe disorder that is very difficult to treat' (Andrews 1999). Various authors report treatment resistance in about $33 \%$ of sufferers. The non-response rate to cognitive-behavioural therapy (CBT) in PTSD is as high as $50 \%$ (Kar 2011) and yet this treatment is purported to have the evidence to justify it as the initial management choice for PTSD by agencies such as the National Institute for Health and Clinical Excellence (NICE; National Collaborating Centre for Mental Health 2005). For comparison, the response rate for selective serotonin reuptake inhibitors (SSRIs) is about $60-80 \%$.

I conducted this review of recent developments in the psychopharmacology of PTSD by searching MEDLINE (from 1946 to 2013) using 'PTSD' as a search term and then scanning reviews on its management for treatments other than first-line antidepressants or CBT. I then ran a second search, using suggestions for pharmacological management of severe, chronic or treatment-resistant PTSD as search terms. Treatments backed by research papers are incorporated in this article.

\section{Psychopharmacology for PTSD}

Although NICE guidance on PTSD states that 'the evidence base for drug treatments in PTSD is very limited' (National Collaborating Centre for Mental Health 2005: p. 19), there are numerous trials indicating that antidepressants are more effective than placebo and at least 18 clinical trials (10 double-blind placebo-controlled, 8 open-label)

\begin{tabular}{|c|c|}
\hline $\begin{array}{l}\text { TABLE } 1 \text { Frequencies of symptoms in } 103 \\
\text { survivors with post-traumatic s }\end{array}$ & $\begin{array}{l}\text { trauma } \\
\text { tress disorder }\end{array}$ \\
\hline Symptom & $\begin{array}{c}\text { Symptom } \\
\text { frequency, \% }\end{array}$ \\
\hline Anxiety at reminders of the trauma & 96 \\
\hline Insomnia & 94 \\
\hline $\begin{array}{l}\text { Intrusive thoughts, memories and sensory } \\
\text { phenomena (e.g. visual flashbacks) }\end{array}$ & 94 \\
\hline Poor concentration & 94 \\
\hline Irritability & 94 \\
\hline Diminished interest in activities or social life & 87 \\
\hline Avoidance behaviour related to the trauma & 80 \\
\hline Recurrent nightmares & 77 \\
\hline Avoidance of thinking about the trauma & 74 \\
\hline Detachment & 74 \\
\hline Foreshortening of expectations of life & 74 \\
\hline Poor appetite & 70 \\
\hline Hypervigilance & 51 \\
\hline More intense startle reaction & 41 \\
\hline Acting as if the trauma were recurring & 41 \\
\hline Restricted affect & 25 \\
\hline Low libido & 24 \\
\hline Low mood & 23 \\
\hline $\begin{array}{l}\text { Inability to recall parts of the trauma (not } \\
\text { secondary to loss of consciousness or } \\
\text { organic trauma) }\end{array}$ & 16 \\
\hline Increased use of alcohol & 13 \\
\hline Increased use of tobacco/other substances & 9 \\
\hline
\end{tabular}

Source: Green 2003
Ben Green is a consultant psychiatrist and Professor of Postgraduate Medical Education and Psychiatry at the University of Chester. He has worked in NHS general adult psychiatry and in independent psychiatric intensive care and low secure units. He has researched and published on the epidemiology of depression and the clinical symptoms of PTSD and teaches at the universities of Liverpool and Chester, where he is developing an MSc course. He has edited and written several books on undergraduate psychiatry and psychopharmacology and is currently editing a book on PTSD and a book on clinical negligence. Correspondence Professor Ben Green, Professor of Postgraduate Medical Education and Psychiatry, University of Chester, Faculty of Health and Social Care, Riverside Campus, Castle Drive, Chester CH1 1SL, UK. Email: b.green@chester.ac.uk 
of atypical antipsychotics for PTSD (Ahearn 2011). I will return to the antipsychotic trials later.

\section{Antidepressants}

Looking at antidepressants, Marshall et al (2001) found statistically significant improvements with paroxetine (20-40 mg/day) compared with placebo on all three PTSD symptom clusters (re-experiencing, avoidance/numbing and hyperarousal) in a study involving 551 patients. In a later study involving 70 people with chronic PTSD, Marshall et al (2007) found significantly different response rates of $67 \%$ for paroxetine v. $27 \%$ for placebo after 10 weeks. Exposure therapy (a form of CBT) plus paroxetine has been found superior in producing remission compared with exposure therapy plus placebo (Schneier 2012).

Sertraline has been found to be superior to placebo in studies by Davidson et al (2001) and Brady et al (2000), which involved 208 and 187 patients respectively.

Fluoxetine has been found superior to placebo in studies by Connor et al (1999) involving 53 patients and van der Kolk et al (1994) including 64 patients.

\section{Is trauma-focused psychotherapy the last word in PTSD treatment?}

The NICE guidelines gave us a simple message in 2005: 'All PTSD sufferers should be offered a course of trauma-focused psychological treatment (trauma-focused cognitive behavioural therapy or eye movement desensitisation and reprocessing)' (National Collaborating Centre for Mental Health 2005: p. 17). The guidelines suggest 8-12 sessions of trauma-focused CBT, but if CBT can begin in the first month after the event, as few as 5 sessions may be needed.

\section{Trauma-focused CBT}

Most psychiatrists would be familiar with the therapeutic uses of CBT and with the concepts behind it, derived from the work of the psychiatrist Aaron T. Beck and others (Beck 1963, 2011). Traumafocused CBT, however, is qualitatively different. It uses additional components such as stimulus confrontation, in which the patient confronts the trauma by reliving it in the imagination or in real life (Seidler 2006). Daily homework thereafter may consist of repeatedly listening to a recording of a verbal narrative of the trauma, with the aim of producing desensitisation.

\section{Eye movement desensitisation and reprocessing}

Another trauma-focused psychotherapy is eye movement desensitisation and reprocessing (EMDR). Based on work by Shapiro (2001),
EMDR is predicated on the theory that traumatic events which overwhelm the cognitive functions of the brain are not processed properly, creating dysfunctional memory systems that reveal themselves as symptoms of PTSD. Therapy involves bilateral brain stimulation using eye movements, sounds or touching while the patient evokes the traumatic visual images or memories and is encouraged to shift between the traumatic past and the safer present. No definitive explanation of how EMDR works is available.

\section{Is EMDR supported by the evidence?}

A wealth of controlled trials using EMDR demonstrate a degree of efficacy, but it is probably fair to say that there are no double-blind randomised controlled trials of the intervention, and that EMDR has not shown superior efficacy to other traumafocused therapies (Lohr 1998). There is also not enough convincing evidence to suggest that the bilateral stimulation techniques are of any use, and some research suggests that EMDR may actually be less effective than CBT (Rothbaum 2005).

In comparative studies, a 50\% reduction in PTSD symptoms can be achieved in $32-53 \%$ of patients receiving 10 sessions of CBT (Hembree 2000), but among the rest at least $14 \%$ drop out of therapy. For exposure models such as trauma-focused CBT, the drop-out rate may be as high as $50 \%$, as many patients have difficulty re-experiencing the trauma involved in stimulus confrontation.

Nevertheless, many patients prefer a non-drug treatment and find interventions such as CBT and EMDR acceptable because they believe that it is not possible to become 'hooked' on psychotherapy. Certainly, there is evidence for the efficacy of traumafocused CBT and EMDR (Hembree 2000; Ponniah 2009), but can they work for severe, chronic illness and provide a 'once and for all' resolution?

\section{The evidence base for trauma-focused CBT and SSRIs}

Research on both psychotherapeutic and pharmacological treatments suffers from short-termism. My MEDLINE searches revealed that randomised controlled trials (RCTs) of SSRIs ran for only 5-12 weeks (Table 2), and RCTs of trauma-focused CBT ran for 5-14 weeks (Table 3). Furthermore, such studies often neglect to include patients with chronic, treatment-resistant PTSD, who frequent more naturalistic settings than the research laboratory or university psychology department. Nor can guidelines or research adequately replicate the real world, where supply and demand dictate the nonavailability of psychotherapies to the masses of people with PTSD, or provide solutions for patients 


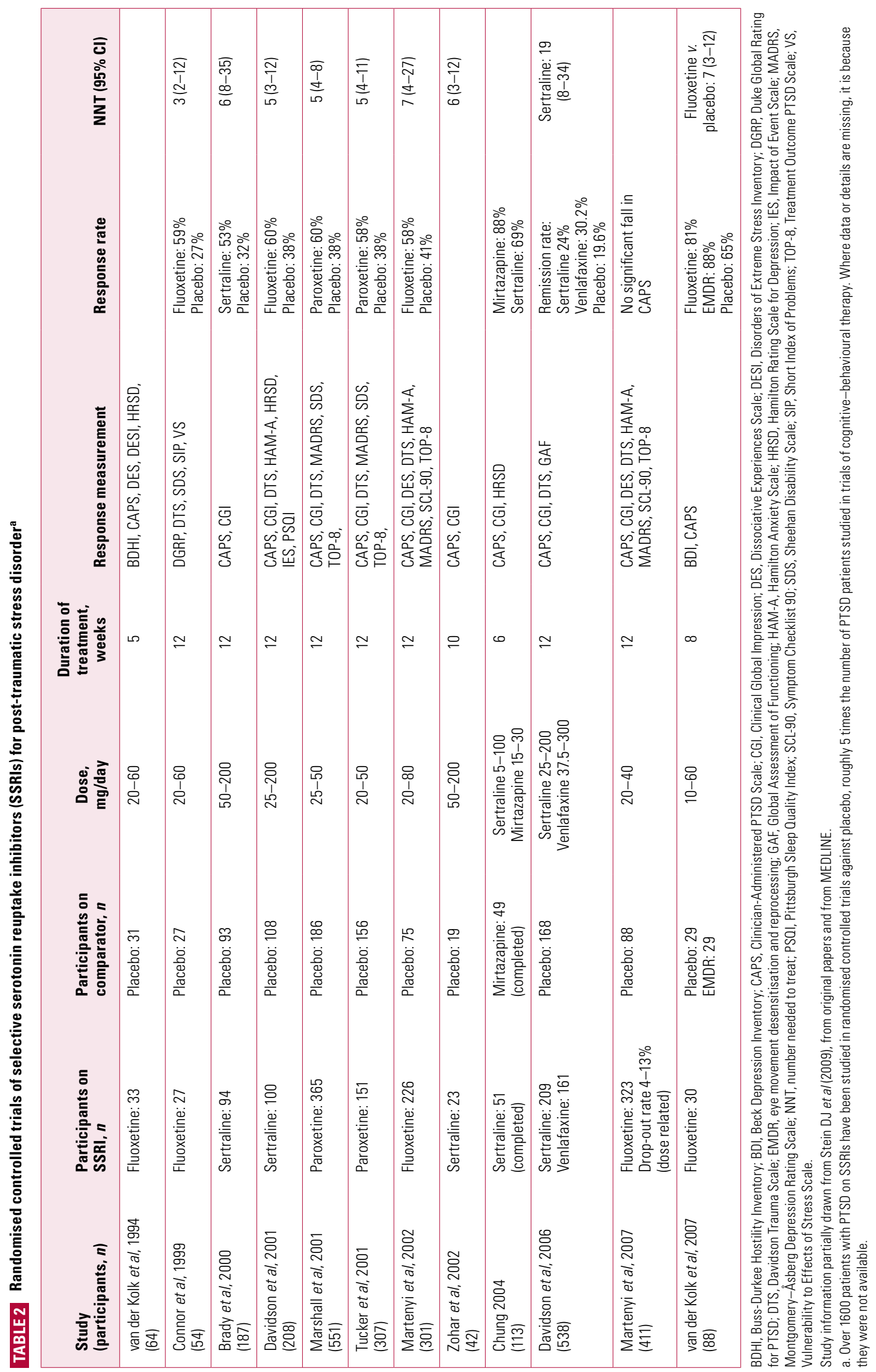




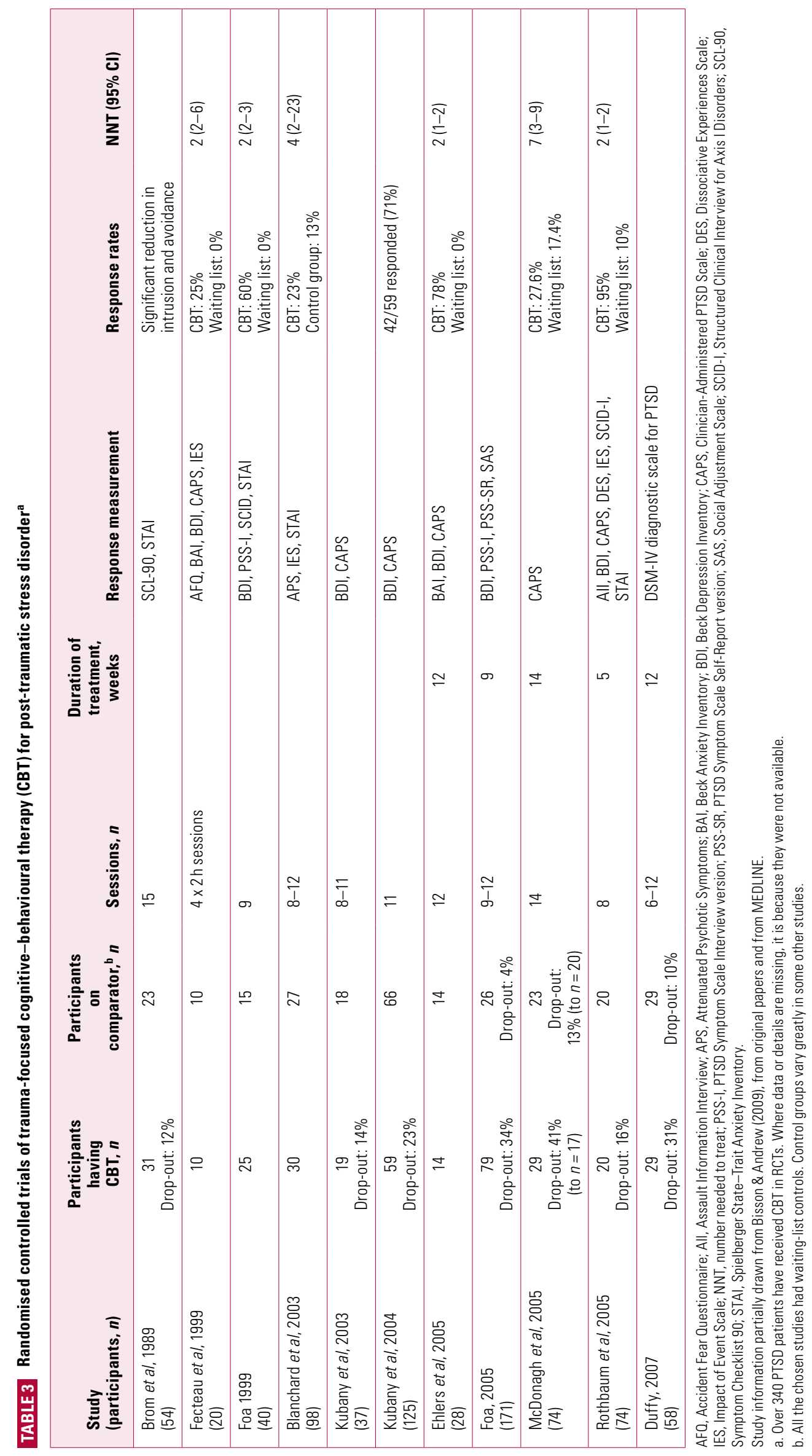


who have graduated from their second course of CBT and relapsed yet again some months later.

\section{NICE recommendations}

The NICE guidelines favour the evidence base for CBT rather than antidepressants. Indeed, the numbers needed to treat (NNTs) in individual trials of CBT are generally more favourable (Tables 2 and 3). Certainly CBT seems more efficacious than alternatives such as psychological debriefing. However, the numbers of patients treated with SSRIs in RCTs far exceed the numbers treated with CBT and the numbers of participants in individual trials are low. Over 1600 people with PTSD have been studied in RCTs comparing SSRIs against placebo, roughly 5 times the number studied in trials of trauma-focused CBT. A further point to consider is that, where it is reported, the drop-out rate for trauma-focused CBT is high (12-41\%), indicating that it is clearly not tolerated by all. The National Health Service (NHS) Health Technology Assessment Programme (Durham 2005) recommends that those espousing psychotherapies need to develop an evidence base involving 'longitudinal research designs over extended periods of time (2-5 years), with large numbers of participants (500+)' before cost-effectiveness could be demonstrated. On the studies that my literature search revealed (Table 3), we are still far from providing such a solid research base for CBT.

\section{The promise of neuroimaging}

We now have evidence of consistent structural and functional neuroimaging changes associated with PTSD (Bremner 2008). Structural changes include volume reduction of the hippocampus by $12 \%$. Reduced hippocampal volume is associated with verbal memory deficits and dissociative experiences. These structural changes can reverse with treatment, as demonstrated in separate studies using paroxetine and valproate (Bremner 2008). Functional changes include hyporesponsivity in medial prefrontal cortical areas during reminder cues. Such changes have been demonstrated in studies involving war veterans with PTSD and also in PTSD suffered by survivors of prolonged childhood sexual abuse. Reminder cues included slides of combat or guided memories of childhood abuse. The medial prefrontal cortex is involved in the inhibition of fear responses in the amygdala, and hyporesponsivity therefore leads to greater activation of the amygdala and consequent PTSD symptoms such as an enhanced startle response.

The promise of neuroimaging is to find treatments that can reverse such structural and functional changes.

\section{Novel treatments}

Of the recently proposed novel treatments for PTSD, it must be said that none has a body of evidence that approaches the evidence base supporting the use of antidepressants and CBT.

\section{Propranolol}

Propranolol is a beta-adrenergic blocker. It blocks the action of adrenaline and noradrenaline on $\beta_{1}$ and $\beta_{2}$ adrenergic receptors, which also results in indirect $\alpha_{1}$ agonism. Various studies have implied that effects of propranolol on the central nervous system may be of relevance to models of PTSD. For instance, propranolol has been shown to reduce the reactivity of the amygdala (Hurlemann 2010) and it may impair memory formation in animal neocortices by reducing synaptic potentiation (Flores 2010). Propranolol may also impair memory formation by attenuating neuropeptide S-induced memory enhancement (Okamura 2011).

Propranolol is licensed in the UK for various conditions, including hypertension and migraine. It is less often prescribed for anxiety disorders in settings such as primary care, the literature on its efficacy as an anxiolytic is very limited. Furthermore, the drug has very real side-effects, which include bradycardia, hypotension and falls, and so certain baseline investigations (electrocardiogram and blood pressure, among others) must be performed before, and monitored during, prescription.

\section{The propranolol protection theory}

There has been media interest over the past decade in a potential protective effect conferred by propranolol against the development of PTSD. The level of media interest could be argued to have been disproportionate, as it was triggered by relatively small-scale studies (e.g. Pitman 2002; Vaiva 2003) that showed a lower incidence of PTSD in people who had been treated with propranolol in the aftermath of trauma. The general concept was that propranolol, as a beta-adrenergic blocker, might prevent the excess activation of the central nucleus of the amygdala and the locus ceruleus after trauma, thought at the time to provide the neurological basis for PTSD.

This promising theory has not been confirmed by larger studies. For instance, research involving 29 children randomised to receive propranolol or placebo within 12 hours of physical trauma showed no significant between-group difference in scores on the Clinician-Administered PTSD Scale for Children and Adolescents (CAPS-CA) at 6 weeks (Nugent 2010).

In another trial, physically injured patients were randomised to receive 14 days of propranolol 
( $n=17)$, gabapentin $(n=14)$ or placebo $(n=17)$ within 48 hours of injury. None of the interventions showed any effect at follow-up (Stein 2007).

Similarly, McGhee et al (2009) found no reduction in PTSD in US soldiers injured in Iraq who had been given propranolol. They reviewed 603 patients at a military burns centre, 226 of whom completed a PTSD checklist. Thirty-one soldiers had received propranolol and 34 matched soldiers had not. The prevalence of PTSD in the propranolol group was $32.3 \%$, against $26.5 \%$ in the comparison group $(P=0.785)$.

The most recent study, a randomised placebocontrolled trial by Hoge et al (2012), evaluated the proactive use of propranolol in a clinical sample of 41 emergency department patients who had just experienced psychological trauma. Participants received either up to $240 \mathrm{mg} /$ day of propranolol or placebo for 19 days. The drug did not significantly affect rates of PTSD diagnosis or severity of symptoms between the groups.

Animal research reports that propranolol given 1 hour after trauma was ineffective in preventing PTSD-like behavioural responses (e.g the startle response or freezing response on reminder cues) (Cohen 2011).

\section{Ketamine}

Ketamine is a glutamatergic $N$-methyl-D-aspartate receptor antagonist which can, very rarely nowadays, be used as an anaesthetic agent. There has been recent interest in the use of intravenous ketamine for depression. A small-scale study of intravenous ketamine in 17 patients with treatmentresistant unipolar depression showed positive effects on mood lasting for a week after a dose of the drug (Zarate 2006). Suicidal ideation was found to reduce in the hours following intravenous administration of ketamine in a study of people with treatment-resistant major depressive disorder (Diazgranados 2010a). There is also research on the use of ketamine in depression associated with chronic regional pain syndrome (Romero-Sandoval 2011) and treatment-resistant bipolar depression (Diazgranados 2010b).

The notion that ketamine might have an off-label part to play in the treatment of PTSD is perhaps less easy to understand, as the drug is associated with side-effects such as tachycardia, nightmares and hallucinations. Nevertheless, interest in ketamine arose from the observation that glutamate, which is released in stress, is important in the generation of dissociative symptoms (Chambers 1999). The Mount Sinai School of Medicine has been conducting a trial (NCT00749203) to see whether ketamine infusions may be a treatment for PTSD. It should be noted that the role ketamine might play in long-term treatment of PTSD would be limited by the need for intravenous administration.

Of three studies of accident and burns victims given ketamine during emergency treatment or surgery, two reported negative effects. In 2005, Schönenberg et al studied injured accident victims who had received either (S)-ketamine or opioids as analgesia in hospital a year previously. They found that retrospectively assessed dissociation, re-experiencing and avoidance behaviour and current PTSD were higher in the (S)-ketamine group.

Further work by Schönenberg et al (2008) found that ketamine aggravated PTSD in burns victims, producing early acute stress disorder, dissociative states, re-experiencing, hyperarousal and avoidance behaviours. The study looked at patients who had received a dose of either ketamine $(n=13)$, opioids $(n=24)$ or non-opioid analgesics $(n=13)$ during initial emergency treatment.

McGhee et al (2008), however, reported reduced levels of PTSD among 119 soldiers with burns who had received ketamine during surgery compared with 28 patients who had not. The PTSD prevalence in the ketamine group was $27 \%$, compared with $46 \%$ in the non-ketamine group $(P=0.044)$.

If ketamine's future in PTSD is not as a treatment, its potential role in stimulating PTSD symptoms may guide further research. One area of interest might be $N$-methyl-D-aspartate receptor agonists (rather than antagonists) such as D-cycloserine, which facilitates learning and hippocampal activity.

\section{MDMA (3,4-methylenedioxymethamphetamine)}

Before its use as a recreational drug ('ecstasy') in the 1990s, MDMA was used as an adjunctive agent to psychotherapy in the 1970s and 1980s. The use of stimulants in psychotherapy for PTSD has a long history. William Sargant used nikethamide and amphetamines in a therapy akin to flooding (exposure therapy) in cases of battle shock during the Second World War (Sargant 1957). Sargant called his technique abreaction, but rather than using sedation, he used stimulants to provoke a sudden and profound emotional crisis or collapse to produce a cure.

The hypothesis behind the use of MDMA in the psychotherapy of PTSD is that MDMA ameliorates fear activation during therapy and increases trust in the therapist, making exposure therapy easier. The drug may also increase blood flow in ventromedial prefrontal and occipital cortex and reduce it in the left amygdala, reversing known PTSD abnormalities (Mithoefer et al, 2011).

The MDMA dose used in therapy is typically between 50 and $125 \mathrm{mg}$. The drug is given when the 
patient is relaxed on a couch, possibly listening to music through headphones. Patients can alternate between the inner experience and talking to the therapist. Sessions are non-directive and patients are encouraged to fully experience and express whatever arises, rather than avoiding or suppressing thoughts. The format for the psychotherapy mimics that used in past decades with lysergic acid diethylamide (LSD) (Pahnke 1971).

Precautions are usually taken to monitor for tachycardia and raised blood pressure. Small-scale studies have also monitored anxiety, depression and neurocognitive abilities. Participants often report tightness of the jaw, nausea, headache, dizziness and anxiety.

Bouso et al (2008) studied six individuals with PTSD who had been treated with 50-75 mg MDMA. The small number reflects the fact that the study was closed down through what the authors termed 'political pressure'. The authors concluded that, as far as their study was concerned, MDMA was 'safe' with 'promising signs of efficacy' and suggested studies with larger samples and higher doses.

Mithoefer et al (2011) studied 20 individuals with PTSD, 12 of whom were allocated to psychotherapy with MDMA and 8 to psychotherapy with placebo. The outcomes measured through the ClinicianAdministered PTSD Scale (CAPS) and Impact of Events Scale (IES) were significantly improved in the MDMA group $(P<0.015$ and $P<0.027)$. At 1 year, $82 \%(14 / 17)$ of the MDMA group still did not meet criteria for PTSD.

\section{Quetiapine}

Antipsychotics are often prescribed off-label for treatment-resistant PTSD (Leslie 2009). A review by Ahearn et al (2011) identified 18 clinical trials (10 double-blind placebo-controlled, 8 open-label) of atypical antipsychotics for PTSD. The authors reported that the double-blind placebo-controlled trials showed only modest effect sizes, but these were positive for risperidone and quetiapine. The greatest improvement was seen on intrusive thoughts and hypervigilance symptom subscales. A 6-month randomised double-blind placebocontrolled multicentre study of adjunctive risperidone published after Ahearn et al's review (Krystal 2011) did not find it to be of significant help in reducing PTSD symptoms.

The evidence indicates a potential role for quetiapine, which is an antagonist at the $\mathrm{D}_{1}$, $\mathrm{D}_{3}$ and $\mathrm{D}_{4}$ dopamine receptors and the 5-HT serotonin receptor. An 8-week open-label trial of adjunctive quetiapine (at a mean dose of $216 \mathrm{mg}$ / day) in 15 adults with severe PTSD reported a $42 \%$ improvement in CAPS score, a $45 \%$ improvement on the Davidson Trauma Scale and a $44 \%$ improvement on the Sheehan Disability Scale (Ahearn 2006).

Another open-label trial, this time involving 6 adolescents, saw improvement in symptom checklist scores with flexibly dosed quetiapine (50-200 mg/ day) over 6 weeks (Stathis 2005).

Kozaric-Kovacic \& Pivac (2007) conducted an open-label study of quetiapine $(25-400 \mathrm{mg} /$ day $)$ for 53 war veterans with PTSD and psychotic symptoms. Quetiapine treatment led to significant reductions in scores on the CAPS, the Positive and Negative Syndrome Scale (PANSS) and Clinical Global Impression - Severity (CGI-S) scale at 2, 6 and 8 weeks.

Two short-term open-label trials (Hamner 2003; Sokolski 2003) showed improvement with lowdose quetiapine (25-300 mg/day) as an adjunct to SSRIs for chronic PTSD. Sokolski et al reported improvements on the DSM-IV PTSD criterion of reexperiencing in $35 \%$ of participants, on avoidance/ numbing in $28 \%$ and on arousal in $65 \%$. Hamner et al reported significant improvement in CAPS and improvement in depression scores.

It is worth noting that several US soldiers and veterans have died while taking high-dose quetiapine (>1600 mg) for PTSD. It is not known whether the drug contributed to the deaths, but the situation has resulted in some controversy in the USA regarding off-label prescribing for the disorder (Perrone 2010).

Quetiapine has various side-effects, including somnolence and postural hypotension (Green 1999).

\section{Prazosin}

Prazosin is an alpha-adrenergic blocker currently licensed for hypertension, cardiac failure, Raynaud's phenomenon and benign prostatic hyperplasia. The drug is also used in the management of scorpion stings. Any potential use for PTSD would be offlabel, but there is now a research base to justify its further study for the disorder (Table 4) arguably a much more substantial base than that for some other treatments considered above. There are important side-effects to be aware of, such as hypotension (especially with the first dose, which should be given in surroundings where monitoring can be done). Other adverse effects include gastrointestinal disturbance, oedema, palpitations, dyspnoea, depression, anxiety and nasal stuffiness.

At least eight studies indicate a role for prazosin in treating PTSD and, given the nature of chronic PTSD and its notable treatment resistance, these are of considerable interest and larger-scale RCTs would be welcome. 
TABLE 4 Studies involving prazosin as a treatment for post-traumatic stress disorder

\begin{tabular}{|c|c|c|c|c|}
\hline Study & Type & $\begin{array}{l}\text { Prazosin dose, } \\
\text { mg/day }\end{array}$ & Participants & Main findings \\
\hline Peskind et al, 2003 & Case series & $2-4$ & $\begin{array}{l}9 \text { older males with Holocaust } \\
\text { or military trauma }\end{array}$ & $\begin{array}{l}\text { Improvement in nightmares and } \\
\text { severity of PTSD }\end{array}$ \\
\hline Raskind et al, 2003 & $\begin{array}{l}\text { Double-blind cross-over study } \\
\text { comparing prazosin with placebo, } \\
\text { over } 20 \text { weeks }\end{array}$ & 9.5(mean, at night) & 10 military veterans & $\begin{array}{l}\text { Improvement in nightmares, } \\
\text { sleep quality and hyperarousal } \\
\text { symptoms }\end{array}$ \\
\hline Taylor et al, 2006 & Case series, from 2004 to 2005 & $2-6$ & 11 patients with chronic PTSD & Reduced startle response \\
\hline Raskind et al, 2007 & $\begin{array}{l}\text { Randomised placebo-controlled } \\
\text { trial lasting } 8 \text { weeks }\end{array}$ & 13 (mean) & $\begin{array}{l}17 \text { patients given prazosin, } 17 \\
\text { given placebo }\end{array}$ & $\begin{array}{l}50 \% \text { reduction in nightmares, } \\
\text { improved sleep quality, overall im- } \\
\text { provement in global clinical status }\end{array}$ \\
\hline Thompson et al, 2008 & Case series & 9.6 (mean, at night) & $\begin{array}{l}22 \text { veterans with chronic } \\
\text { PTSD }\end{array}$ & $\begin{array}{l}\text { Improvements in nightmares, } \\
\text { non-nightmare awakenings and } \\
\text { sleep quality }\end{array}$ \\
\hline Taylor et al, 2008 & $\begin{array}{l}\text { Randomised placebo-controlled, } \\
\text { cross-over trial }\end{array}$ & $2-6$ & 13 patients with chronic PTSD & $\begin{array}{l}\text { Increase in sleep quantity, } \\
\text { increased RAM sleep, reduced } \\
\text { nightmares }\end{array}$ \\
\hline Boynton et al, 2009 & $\begin{array}{l}\text { Case series receiving } 8 \text { weeks of } \\
\text { prazosin }\end{array}$ & $1-6$ & $\begin{array}{l}23 \text { refugees with chronic } \\
\text { PTSD }\end{array}$ & $\begin{array}{l}\text { Marked improvement in } \\
\text { PTSD severity in } 6 \text {, moderate } \\
\text { improvement in } 11 \text { and minimal } \\
\text { improvement in } 6\end{array}$ \\
\hline Byers et al, 2010 & $\begin{array}{l}\text { Randomised controlled trial } \\
\text { comparing prazosin with } \\
\text { quetiapine, over } 6 \text { months }\end{array}$ & $1-25$ & $\begin{array}{l}62 \text { patients with treatment- } \\
\text { resistant PTSD given prazosin } \\
\text { and } 175 \text { given quetiapine }\end{array}$ & $\begin{array}{l}\text { About } 61 \% \text { response rate for both } \\
\text { prazosin and quetiapine; fewer } \\
\text { side-effects in prazosin group }\end{array}$ \\
\hline Germain et al, 2012 & $\begin{array}{l}\text { 8-week randomised placebo- } \\
\text { controlled study comparing } \\
\text { prazosin with behavioural } \\
\text { sleep intervention targeting } \\
\text { nightmares and sleep } \\
\text { disturbances, and placebo }\end{array}$ & $\begin{array}{l}8.9 \text { (mean, at night; } \\
\text { range } 1-15)\end{array}$ & $\begin{array}{l}50 \text { US military veterans with } \\
\text { chronic sleep disturbances; } \\
18 \text { received prazosin, } \\
17 \text { a behavioural sleep } \\
\text { intervention, } 15 \text { placebo }\end{array}$ & $\begin{array}{l}\text { Treatment groups showed } \\
\text { reduction in daytime PTSD } \\
\text { symptoms and insomnia, with } \\
\text { a } 62 \% \text { in the treatment groups } \\
\text { showing sleep improvements } \mathrm{V} \text {. } \\
25 \% \text { in placebo group }\end{array}$ \\
\hline
\end{tabular}

\section{Conclusions}

Traditional PTSD treatments recommended by agencies such as NICE (e.g. CBT, EMDR and SSRIs) do have an evidence base, but they are of limited efficacy and trauma-focused CBT in particular has a high drop-out rate. Developments in neuroimaging could lead to new pharmacological treatments. Although current research has not demonstrated a significant role for either ketamine or propranolol, studies of prazosin for the treatment of severe, chronic PTSD suggest anti-nightmare efficacy and long-term tolerability. Larger-scale RCTs on prazosin are now justified.

\section{Acknowledgements}

I am indebted to Dr Chris Cates for his advice on the calculation and presentation of NNTs.

\section{References}

Ahearn EP, Mussey M, Johnson C, et al (2006) Quetiapine as an adjunctive treatment for post-traumatic stress disorder: an 8 week open-label study. International Clinical Psychopharmacology 21: 29-33.

Ahearn EP, Juergens T, Cordes T, et al (2011) A review of atypical antipsychotic medications for posttraumatic stress disorder. International Clinical Psychopharmacology 26: 193-200.

Andrews G, Jenkins R (1999) Management of Mental Disorders (Vol. 1). World Health Organization Collaborating Centres in Mental Health.
Beck AT (1963) Thinking and depression - idiosyncratic content and cognitive distortions. Archives of General Psychiatry 9: 324-33.

Beck AT, Dozois DJA (2011) Cognitive therapy: current status and future directions. Annual Review of Medicine 62: 397-409.

Bisson J, Andrew M (2009) Psychological treatment of post traumatic stress disorder (PTSD). Cochrane Library (issue 1) (doi: 10.1002/14651858. CD003388.pub3)

*Blanchard EB, Hickling EJ, Devineni T, et al (2003) A controlled evaluation of cognitive behavioural therapy for posttraumatic stress in motor vehicle accident survivors. Behaviour Research and Therapy 41 . 79-96.

Bouso JC, Doblin R, Farré M, et al (2008) MDMA-assisted psychotherapy. Journal of Psychoactive Drugs 40: 225-36.

*Boynton L, Bentley J, Strachan E, et al (2009) Preliminary findings concerning the use of prazosin for the treatment of posttraumatic nightmares in a refugee population. Journal of Psychiatric Practice 15: $454-9$

*Brady K, Pearlstein T, Asnis GM, et al (2000) Efficacy and safety of sertraline treatment of posttraumatic stress disorder: a randomized controlled trial. JAMA 283: 1837-44.

Bremner JD, Elzinga B, Schmahl C, et al (2008) Structural and functional plasticity of the human brain in posttraumatic stress disorder. Progress in Brain Research 167: 171-86.

*Brom D, Kleber RJ, Defares PB (1989) Brief psychotherapy for posttraumatic stress disorders. Journal of Consulting and Clinical Psychology 57: 607-12.

*Byers MG, Allison KM, Wendel CS, et al (2010) Prazosin versus quetiapine for nighttime posttraumatic stress disorder symptoms in veterans: an assessment of long-term comparative effectiveness and safety. Journal of Clinical Psychopharmacology 30: 225-9. 
Chambers RA, Bremner JD, Moghaddam B, et al (1999) Glutamate and post-traumatic stress disorder: toward a psychobiology of dissociation. Seminars in Clinical Neuropsychiatry 4: 274-81.

${ }^{*}$ Chung MY, Min KH, Jun YJ, et al (2004) Efficacy and tolerability of mirtazapine and sertraline in Korean veterans with posttraumatic stress disorder: a randomized open label trial. Human Psychopharmacology 19 : 489-94.

Cohen H, Kaplan Z, Koresh 0, et al (2011) Early post-stressor intervention with propranolol is ineffective in preventing posttraumatic stress responses in an animal model for PTSD. European Neuropsychopharmacology 21: 230-40.

*Connor KM, Sutherland SM, Tupler LA, et al (1999) Fluoxetine in posttraumatic stress disorder: randomised, double-blind study. British Journal of Psychiatry 175: 17-22.

*Davidson JRT, Rothbaum BO, van der Kolk BA, et al (2001) Multicenter, double-blind comparison of sertraline and placebo in the treatment of posttraumatic stress disorder. Archives of General Psychiatry 58: 485-92.

*Davidson J, Rothbaum B0, Tucker P, et al (2006) Venlafaxine extended release in posttraumatic stress disorder: a sertraline- and placebocontrolled study. Journal of Clinical Psychopharmacology 26: 259-67.

Diazgranados N, Ibrahim LA, Brutsche NE, et al (2010a) Rapid resolution of suicidal ideation after a single infusion of an $\mathrm{N}$-methyl-D-aspartate antagonist in patients with treatment-resistant major depressive disorder. Journal of Clinical Psychiatry 71: 1605-11.

Diazgranados N, Ibrahim L, Brutsche NE, et al (2010b) A randomized add-on trial of an $\mathrm{N}$-methyl-D-antagonist in treatment-resistant bipolar depression. Archives of General Psychiatry 67: 793-802.

*Duffy M, Gillespie K, Clark DM (2007) Post-traumatic stress disorder in the context of terrorism and other civil conflict in Northern Ireland: randomised controlled trial. BMJ 334: 1147-50.

Durham RC, Chambers JA, Power KG, et al (2005) Long-term outcome of cognitive behaviour therapy (CBT) clinical trials in central Scotland. Health Technology Assessment 9 (42): 1-174.

*Ehlers A, Clark DM, Hackmann A, et al (2005) Cognitive therapy for post-traumatic stress disorder: development and evaluation. Behaviour Research and Therapy 43: 413-31.

*Fecteau G, Nicki R (1999) Cognitive behavioural treatment of post traumatic stress disorder after motor vehicle accident. Behavioural and Cognitive Psychotherapy 27: 201-4.

Flores 0, Núñez H, Pérez H, et al (2010) Beta-adrenoceptor blockade depresses molecular and functional plasticities in the rat neocortex. Brain Research Bulletin 82: 284-8.

*Foa EB, Dancu CV, Hembree EA, et al (1999) A comparison of exposure therapy, stress inoculation training, and their combination for reducing posttraumatic stress disorder in female assault victims. Journal of Consulting and Clinical Psychology 67: 194-200.

*Foa EB, Hembree EA, Cahill SP, et al (2005) Randomized trial of prolonged exposure for posttraumatic stress disorder with and without cognitive restructuring: outcome at academic and community clinics. Journal of Consulting and Clinical Psychology 73: 953-64.

*Germain A, Richardson R, Moul DE, et al (2012) Placebo-controlled comparison of prazosin and cognitive-behavioral treatments for sleep disturbances in US Military Veterans. Journal of Psychosomatic Research 72: 89-96.

Green B (1999) Focus on quetiapine. Current Medical Research and Opinion 15: 145-51.

Green B (2003) Post-traumatic stress disorder: symptom profiles in men and women. Current Medical Research and Opinion 19: 200-4.

Hamner MB, Deitsch SE, Brodrick PS, et al (2003) Quetiapine treatment in patients with posttraumatic stress disorder: an open trial of adjunctive therapy. Journal of Clinical Psychopharmacology 23: 15-20.

Hembree EA, Foa EB (2000) Posttraumatic stress disorder: psychological factors and psychosocial interventions. Journal of Clinical Psychiatry 61 (suppl 7): 33-9.

Hoge EA, Worthington JJ, Nagurney JT, et al (2012) Effect of acute posttrauma propranolol on PTSD outcome and physiological responses during script-driven imagery. CNS Neuroscience \& Therapeutics 18: 21-7.
Hurlemann R, Walter H, Rehme AK, et al (2010) Human amygdala reactivity is diminished by the beta-noradrenergic antagonist propranolol. Psychological Medicine 40: 1839-48.

Kar N (2011) Cognitive behavioral therapy for the treatment of posttraumatic stress disorder: a review. Neuropsychiatric Disease and Treatment 7: 167-81.

Kessler RC, Chiu WT, Demler 0, et al (2005) Prevalence, severity, and comorbidity of twelve-month DSM-IV disorders in the National Comorbidity Survey Replication (NCS-R). Archives of General Psychiatry 62: 617-27.

Kozaric-Kovacic D, Pivac N (2007) Quetiapine treatment in an open trial in combat-related post-traumatic stress disorder with psychotic features. International Journal of Neuropsychopharmacology 10: 253-61.

Krystal JH (2011) Adjunctive risperidone treatment for antidepressant resistant symptoms of chronic military service related PTSD. JAMA 306 : 493-502.

Kubany ES, Hill EE, Owens JA (2003) Cognitive trauma therapy for battered women with PTSD: preliminary findings. Journal of Traumatic Stress 16: 81-91.

Kubany ES, Hill EE, Owens JA, et al (2004) Cognitive trauma therapy for battered women with PTSD (CTT-BW). Journal of Consulting and Clinical Psychology 72: 3-18.

Leslie DL, Mohamed S, Rosenheck RA (2009) Off-label use of antipsychotic medications in the Department of Veterans Affairs health care system. Psychiatric Services 60: 1175-81.

Lohr JM, Tolin DF, Lilienfeld SO (1998) Efficacy of eye movement desensitization and reprocessing: implications for behavior therapy. Behavior Therapy 29: 123-56.

*Marshall RD, Beebe KL, Oldham M, et al (2001) Efficacy and safety of paroxetine treatment for chronic PTSD: a fixed-dose, placebo-controlled study. American Journal of Psychiatry 158: 1982-8.

Marshall RD, Lewis-Fernandez R, Blanco C, et al (2007) A controlled trial of paroxetine for chronic PTSD, dissociation, and interpersonal problems in mostly minority adults. Depression and Anxiety 24: 77-84.

*Martenyi F, Brown EB, Zhang H, et al (2002) Fluoxetine versus placebo in posttraumatic stress disorder. Journal of Clinical Psychiatry 63: 199-206.

*Martenyi F, Brown EB, Caldwell CD (2007) Failed efficacy of fluoxetine in the treatment of posttraumatic stress disorder: results of a fixed-dose, placebo-controlled study. Journal of Clinical Psychopharmacology 27: 166-70.

*McDonagh A, Friedman M, McHugo G, et al (2005) Randomized trial of cognitive-behavioral therapy for chronic posttraumatic stress disorder in adult female survivors of childhood sexual abuse. Journal of Consulting and Clinical Psychology 73: 515-24.

McGhee LL, Maani CV, Garza TH, et al (2008) The correlation between ketamine and posttraumatic stress disorder in burned service members. Journal of Trauma 64: S195-8.

McGhee LL, Maani CV, Garza TH, et al (2009) The effect of propranolol on posttraumatic stress disorder in burned service members. Journal of Burn Care Research 30: 92-7.

Mithoefer MC, Wagner MT, Mithoefer AT, et al (2011) The safety and efficacy of $\{+/-\} 3,4$-methylenedioxymethamphetamine-assisted psychotherapy in subjects with chronic, treatment-resistant posttraumatic stress disorder: the first randomized controlled pilot study. Journal of Psychopharmacology 25: 439-52.

National Collaborating Centre for Mental Health (2005) Post-Traumatic Stress Disorder (PTSD): The Management of PTSD in Adults and Children in Primary and Secondary Care (Clinical Guideline 26). National Institute for Clinical Excellence.

Nugent NR, Christopher NC, Crow JP, et al (2010 The efficacy of early propranolol administration at reducing PTSD symptoms in pediatric injury patients: a pilot study. Journal of Trauma Stress 23: 282-7.

Okamura N, Garau C, Duangdao DM, et al (2011) Neuropeptide S enhances memory during the consolidation phase and interacts with noradrenergic systems in the brain. Neuropsychopharmacology 36: 744-52.

Pahnke WN, Kurland AA, Unger S, et al (1971) The experimental use of psychedelic (LSD) psychotherapy. Internationale Zeitschrift für klinische Pharmakologie, Therapie, und Toxikologie 4: 446-54.
MCO answers

1 a $\quad 2$ b $\quad 3 d \quad 4$ e $\quad 5 d$ 
Perrone M (2010) Questions loom over drug given to sleepless vets. Washington Times 30 August.

*Peskind ER, Bonner LT, Hoff DJ, et al (2003) Prazosin reduces traumarelated nightmares in older men with chronic posttraumatic stress disorder. Journal of Geriatric Psychiatry and Neurology 16: 165-71.

Pitman RK, Sanders KM, Zusman RM, et al (2002) Pilot study of secondary prevention of posttraumatic stress disorder with propranolol. Biological Psychiatry 51: 189-92.

Ponniah K, Hollon SD (2009) Empirically supported psychological treatments for adult acute stress disorder and posttraumatic stress disorder: a review. Depression and Anxiety 26: 1086-109.

*Raskind MA, Peskind ER, Kanter ED, et al (2003) Reduction of nightmares and other PTSD symptoms in combat veterans by prazosin: a placebo-controlled study. American Journal of Psychiatry 160: 371-3.

*Raskind MA, Peskind ER, Hoff DJ, et al (2007) A parallel group placebo controlled study of prazosin for trauma nightmares and sleep disturbance in combat veterans with post-traumatic stress disorder. Biological Psychiatry 61: 928-34.

Romero-Sandoval EA (2011) Depression and pain: does ketamine improve the quality of life of patients in chronic pain by targeting their mood? Anesthesiology 115: 687-8.

Rothbaum BO, Astin MC, Marsteller F (2005) Prolonged exposure versus eye movement desensitization and reprocessing (EMDR) for PTSD rape victims. Journal of Traumatic Stress 18: 607-16.

Sargant W (1957) Battle for the Mind. Heinemann.

Schneier FR, Neria Y, Pavlicova M, et al (2012) Combined prolonged exposure therapy and paroxetine for PTSD related to the World Trade Center attack: a randomized controlled trial. American Journal of Psychiatry 169: 80-8.

Schönenberg M, Reichwald U, Domes G, et al (2005) Effects of peritraumatic ketamine medication on early and sustained posttraumatic stress symptoms in moderately injured accident victims. Psychopharmacology 182: 420-5.

Schönenberg M, Reichwald U, Domes G, et al (2008) Ketamine aggravates symptoms of acute stress disorder in a naturalistic sample of accident victims. Journal of Psychopharmacology 22: 493-7.

Seidler GH, Wagner FE (2006) Comparing the efficacy of EMDR and trauma-focused cognitive-behavioral therapy in the treatment of PTSD: a meta-analytic study. Psychological Medicine 36: 1515-22.

Shapiro F (2001) Eye Movement Desensitization of Reprocessing: Basic Principles, Protocols and Procedures (2nd edn). Guilford Press.

Sokolski KN, Denson TF, Lee RT, et al (2003) Quetiapine for treatment of refractory symptoms of combat-related post-traumatic stress disorder. Military Medicine 168: 486-9.
Stathis S, Martin G, McKenna JG (2005) A preliminary case series on the use of quetiapine for posttraumatic stress disorder in juveniles within a youth detention center. Journal of Clinical Psychopharmacology 25: 539-44.

Stein MB, Kerridge C, Dimsdale JE, et al (2007) Pharmacotherapy to prevent PTSD: Results from a randomized controlled proof-of-concept trial in physically injured patients. Journal of Traumatic Stress 20: 923-32

Stein DJ, Ipser JC, Seedat S (2009) Pharmacotherapy for post traumatic stress disorder (PTSD). Review. Cochrane Library (issue 1) (doi: 10.1002/14651858.CD006239).

*Taylor FB, Lowe K, Thompson C, et al (2006) Daytime prazosin reduces psychological distress to trauma specific cues in civilian trauma posttraumatic stress disorder. Biological Psychiatry 59: 577-81.

*Taylor FB, Martin P, Thompson C, et al (2008) Prazosin effects on objective sleep measures and clinical symptoms in civilian trauma posttraumatic stress disorder: a placebo-controlled study. Biological Psychiatry 63: 629-32.

*Thompson CE, Taylor FB, McFall ME, et al (2008) Nonnightmare distressed awakenings in veterans with posttraumatic stress disorder: response to prazosin. Journal of Traumatic Stress 21: 417-20.

*Tucker P, Zaninelli R, Yehuda R, et al (2001) Paroxetine in the treatment of chronic posttraumatic stress disorder: results of a placebo-controlled, flexible-dosage trial. Journal of Clinical Psychiatry 62: 860-8.

Vaiva G, Ducrocq F, Jezequel K, et al (2003) Immediate treatment with propranolol decreases posttraumatic stress disorder two months after trauma. Biological Psychiatry 54: 947-9.

van der Kolk BA, Dreyfuss D, Michaels M, et al (1994) Fluoxetine in posttraumatic stress disorder. Journal of Clinical Psychiatry 55: $517-22$

*van der Kolk BA, Spinazzola J, Blaustein ME, et al (2007) A randomized clinical trial of eye movement desensitization and reprocessing (EMDR), fluoxetine, and pill placebo in the treatment of posttraumatic stress disorder: treatment effects and long-term maintenance. Journal of Clinical Psychiatry 68: 37-46.

Zarate CA Jr, Singh JB, Carlson PJ, et al (2006) A randomized trial of an $\mathrm{N}$-methyl-D-aspartate antagonist in treatment-resistant major depression. Archives of General Psychiatry 63: 856-64.

*Zohar J, Amital D, Miodownik C, et al (2002) Double-blind placebocontrolled pilot study of sertraline in military veterans with posttraumatic stress disorder. Journal of Clinical Psychopharmacology 22. $190-5$

*An asterisk denotes studies listed in Tables 2, 3 and 4.

\section{MCOs}

Select the single best option for each question stem

\section{Prazosin is:}

a an alpha-adrenergic blocker

b a beta-adrenergic antagonist

c an antagonist at $D_{1}, D_{3}$ and $D_{4}$ receptors

d a glutamatergic drug

e a selective serotonin reuptake inhibitor.

\section{Trauma-focused CBT:}

a has efficacy rates of $80 \%$ within 10 weeks of starting therapy

b should be offered to all sufferers of PTSD, according to the 2005 NICE guidelines

c is demonstrably superior to EMDR for PTSD

$d$ has a negligible drop-out rate of less than $5 \%$

e has less efficacy than psychological debriefing in the treatment of PTSD.

\section{Propranolol:}

$a$ is licensed in the UK for the treatment of anxiety

b prevents PTSD if given immediately after trauma, according to substantial, replicated double-blind randomised trials

c can be prescribed for anxiety without first performing any physical examination or investigations

d can cause bradycardia

$\mathrm{e}$ is a specific alpha-adrenergic blocker.

\section{Quetiapine:}

a is superior to prazosin in treating chronic PTSD

$b$ is licensed in the UK for the treatment of PTSD

$c$ is an agonist at $D_{1}, D_{3}$ and $D_{4}$ receptors

$\mathrm{d}$ has been associated with fatalities at low doses in US military personnel

e can cause postural hypotension.
5 PTSD:

a has a lifetime prevalence of $4 \%$

b responds to SSRIs within 2 months in $90 \%$ of cases

c occurs in less than $10 \%$ of people involved in road traffic accidents

$\mathrm{d}$ is associated with increased alcohol consumption

e is associated with irritability in less than $50 \%$ of cases. 